\title{
The Relationship between Religion and Mental Disorders in a Korean Population
}

\author{
Jong-lk Park ${ }^{1}$, Jin Pyo Hong ${ }^{2}$, Subin Park ${ }^{2}$ and Maeng-Je Cho ${ }^{3 凶}$ \\ ${ }^{1}$ Department of Psychiatry, Kangwon National University College of Medicine, Chuncheon, Korea \\ ${ }^{2}$ Department of Psychiatry, University of Ulsan College of Medicine, Seoul, Korea \\ ${ }^{3}$ Department of Psychiatry and Behavioral Science, Seoul National University College of Medicine, Seoul, Korea
}

\begin{abstract}
Objective The question of whether religion has beneficial or detrimental effects on the mental well-being of the adult individual is debatable. Because most Korean citizens are free to select their own religion, there is a higher proportion of non-believers than believers among the Korean population. The aim of this research was to investigate the association between spiritual values and Diagnostic and Statistical Manual of Mental Disorders, Fourth Edition mental disorders in Korea across all types of belief systems, including Koreans not affiliated with a particular religion.

Methods The Korean version of the Composite International Diagnostic Interview 2.1 was used to interview 6,275 people across South Korea in 2001. While controlling for age and sex, we used logistic regression to analyze the relationship between mental disorders (both current and past) and the types of religion and spiritual values.

Results Strong spiritual values were positively associated with increased rates of current depressive disorder and decreased rates of current alcohol use disorder. Using "atheist" as the reference category, Catholics had higher lifetime odds of single episodes of depression whilst Protestants had higher lifetime odds of anxiety disorder and lower lifetime odds of alcohol use disorders.

Conclusion The results of this study suggest that depressive episodes often lead to a search for spirituality and that religion may be helpful in overcoming depression or becoming less vulnerable to relapsing. The associations between religion, spiritual values, and mental health have not been fully elucidated and warrant further exploration.

Psychiatry Investig 2012;9:29-35
\end{abstract}

Key Words Prevalence, Religion, Spirituality, Mental disorders.

\section{INTRODUCTION}

The effect of religion on mental health has long been debated and remains controversial despite some positive findings in reviews of empirical research. ${ }^{1-4}$ The most plausible explanation of these mixed results is that the relationship between religion and mental health is not robust and is sensitive to the definitions adopted, the measures employed, and the samples studied. ${ }^{5}$

Although many studies have been conducted on mental illness among people with different religious affiliations, al-

Received: March 3, 2010 Revised: June 7, 2011

Accepted: June 14, 2011 Available online: January 11, 2012

$\triangle$ Correspondence: Maeng-Je Cho, $\mathrm{MD}, \mathrm{PhD}$

Department of Psychiatry and Behavioral Science, Seoul National University College of Medicine, 101 Daehak-ro, Jongno-gu, Seoul 110-744, Korea Tel: +82-2-2072-3155, Fax: +82-2-744-7241, E-mail: mjcho@plaza.snu.ac.kr

(c) This is an Open Access article distributed under the terms of the Creative Commons Attribution Non-Commercial License (http://creativecommons.org/licenses/bync/3.0) which permits unrestricted non-commercial use, distribution, and reproduction in any medium, provided the original work is properly cited. most all have focused on Christian denominations. Therefore, few studies have explored the association between mental health and religiosity across a wide variety of types of religious believers.

Although the last Korean dynasty was based on Confucianism, which had been imported from ancient China approximately 700 years ago, most Koreans adopted Buddhist beliefs until the early $20^{\text {th }}$ century. However, the Christian population, including Protestants and Catholics, has increased in the past several decades, and Christianity has now become the most popular religion in Korea. Nonetheless, the proportion of atheists remains substantial because religion is not obligatory in Korean society. Another factor affecting religious adherence is the negligible number of minor religious groups among Korean nationals, which reflects the ethnic homogeneity of the country. ${ }^{6}$

Spirituality can be defined as a personal quest for understanding answers to ultimate questions about life, meaning, and the relationship with the sacred. Because religious prac- 
tices and rituals differ, spirituality may be associated with mental health, regardless of the type of religion. ${ }^{\text {? }}$

The aim of this study was to compare the rates of three psychiatric disorders (major depressive disorder, anxiety disorder, and alcohol use disorder) according to type of religion or spiritual values in a nationwide sample of Korea.

\section{METHODS}

\section{Data collection}

The Korean Epidemiologic Catchment Area study was conducted between June 1 and November 30, 2001 to collect mental health-related information about the Korean population aged 18-64 years living in private dwellings. This survey utilized the diagnostic definitions in the DSM-IV ${ }^{8}$ and the Korean version of the Composite International Diagnostic Interview 2.1 (K-CIDI 2.1). ${ }^{9}$ The frequencies of mental disorders were transformed by weighting and adjusting the data to approximate the national population contributors of age and gender in each catchment area, as defined by the Korean National Statistical Office's 2000 census. ${ }^{6}$ More detailed information on this epidemiologic survey has been previously described. ${ }^{10}$

\section{Study measures}

\section{Past and current mental disorders}

A current mental disorder was defined as the occurrence of an episode that met the diagnostic criteria of any mental disorder during the preceding 12 months. In addition, the term "past mental disorder" was used to categorize cases with a lifetime history of any mental disorder that fulfilled the diagnostic criteria but with no episodes during the preceding 12 months.

\section{Type of religion and spiritual values}

We asked the respondents two questions: "What is your major religion in most of your life?" and "How much have spiritual values played an important role in your life?" Spiritual values were evaluated using quartiles of one (none) to four (high).

Minor religions were excluded in the analysis due to cell sizes below five.

\section{Statistical analysis}

Group differences in the sociodemographic variables and the stated importance of spiritual values were computed using the chi-squared and ANOVA tests We also applied logistic regression models to determine the lifetime, one-year, and past odds of mental disorders based on the type of religion, using "atheist" as the reference category. Each mental disorder was analyzed separately and adjusted for age and sex. In addition, a series of logistic regression analyses derived odds ratios and 95\% confidence intervals using the past or current mental disorders as the main outcome variables and DSMIV SP and spiritual values as the predictor, after adjusting for age, sex, and type of religion. All statistical analyses were conducted using SPSS version 14.0.

\section{RESULTS}

\section{Sociodemographic profiles according to type of religion}

Universally, females reported more religious affiliation across three religious groups (64.0\% for Buddhism, 63.9\% for Christianity, and $67.4 \%$ for Catholicism) than males. Buddhism was more popular among older, less-educated, and lower-income individuals.

Spiritual values were higher among Christians than among Buddhists (Table 1).

\section{Prevalence of mental disorders by type of religion}

The lifetime prevalence of a single episode of major depressive disorder was higher in Catholics than in atheists. Moreover, the lifetime prevalence of anxiety disorder was higher in Protestants and Catholics than in atheists. In contrast, the lifetime prevalence of alcohol use disorder was lower in Protestants than in atheists. There were no significant differences between the types of religion in either the lifetime or the one-year prevalence of any mental disorder (Table 2). After controlling for sex and age, we compared the odds ratios for prevalence of lifetime, one-year, and past disorders according to type of religion, using "atheist" as the reference category.

Protestants had higher ORs for lifetime anxiety disorder and lower ORs for lifetime alcohol use disorder. Catholics had higher ORs for lifetime and past prevalence of single episodes of major depressive disorder but not for one-year prevalence (Table 3).

\section{Association of current and past mental disorders with spiritual values}

The results of the logistic regression analysis indicate that stronger spiritual values were associated with higher odds of suffering current depression (Table 4).

Conversely, there was a significant negative correlation between the odds ratio of alcohol use disorder and the reported importance of spiritual values. There were no significant differences in the prevalence rates of past mental disorders according to spiritual values (Figure 1). 
Table 1. Sociodemographic profiles according to religion in the Korean Epidemiologic Catchment Area (KECA) Study (N=6,275)

\begin{tabular}{|c|c|c|c|c|c|}
\hline & Buddhists & Protestants & Catholics & Atheists & p-value* \\
\hline Sex & & & & & 0.000 \\
\hline Male & $475(36.0 \%)$ & $529(36.1 \%)$ & $154(32.6 \%)$ & $1541(52.9 \%)$ & \\
\hline Female & $845(64.0 \%)$ & $936(63.9 \%)$ & $318(67.4 \%)$ & $1374(47.1 \%)$ & \\
\hline Age, year & & & & & 0.000 \\
\hline $18-24$ & $72(5.5 \%)$ & $163(11.2 \%)$ & $38(8.2 \%)$ & $295(10.2 \%)$ & \\
\hline $25-34$ & $218(16.7 \%)$ & $382(26.3 \%)$ & $94(20.2 \%)$ & $831(28.7 \%)$ & \\
\hline $35-44$ & $344(26.4 \%)$ & $393(27.1 \%)$ & $145(31.1 \%)$ & $855(29.5 \%)$ & \\
\hline $45-54$ & $250(19.2 \%)$ & $280(19.3 \%)$ & $96(20.6 \%)$ & $445(15.4 \%)$ & \\
\hline $55-64$ & $421(32.3 \%)$ & $232(16.0 \%)$ & $93(20.0 \%)$ & $471(16.3 \%)$ & \\
\hline Mean (SD) & $45.77(12.76)$ & $40.15(12.68)$ & $42.39(12.42)$ & $39.67(12.48)$ & 0.000 \\
\hline Education, year & & & & & 0.000 \\
\hline $0-11$ & $670(50.8 \%)$ & $432(29.5 \%)$ & $148(31.4 \%)$ & $950(32.6 \%)$ & \\
\hline 12 & $431(32.7 \%)$ & $533(36.4 \%)$ & $165(35.0 \%)$ & $1156(39.7 \%)$ & \\
\hline $13-15$ & $96(7.3 \%)$ & $222(15.2 \%)$ & $54(11.4 \%)$ & $346(11.9 \%)$ & \\
\hline$\geq 16$ & $123(9.3 \%)$ & $278(19.0 \%)$ & $105(22.2 \%)$ & $463(15.9 \%)$ & \\
\hline Income, million won & & & & & 0.000 \\
\hline $0-50$ & $240(20.7 \%)$ & $206(16.1 \%)$ & $68(15.9 \%)$ & $390(14.8 \%)$ & \\
\hline $51-150$ & $530(45.7 \%)$ & $493(38.5 \%)$ & $155(36.3 \%)$ & $1155(44.0 \%)$ & \\
\hline $151-300$ & $299(25.8 \%)$ & $456(35.6 \%)$ & $151(35.4 \%)$ & $872(33.2 \%)$ & \\
\hline$\geq 301$ & $92(7.9 \%)$ & $127(9.9 \%)$ & $53(12.4 \%)$ & $210(8.0 \%)$ & \\
\hline Marital status & & & & & 0.000 \\
\hline Married & $1,036(78.5 \%)$ & $1,045(71.4 \%)$ & $344(72.9 \%)$ & $2080(71.4 \%)$ & \\
\hline Separated/divorced & $134(10.2 \%)$ & $115(7.9 \%)$ & $45(9.5 \%)$ & $183(6.3 \%)$ & \\
\hline Never married & $150(11.4 \%)$ & $303(20.7 \%)$ & $83(17.6 \%)$ & $650(22.3 \%)$ & \\
\hline Importance of spirituality & & & & & 0.000 \\
\hline None & $106(8.1 \%)$ & $74(5.2 \%)$ & $17(3.7 \%)$ & $1,052(45.6 \%)$ & \\
\hline Low & $531(40.7 \%)$ & $264(18.4 \%)$ & $120(26.1 \%)$ & $1,047(45.4 \%)$ & \\
\hline Moderate & $465(35.7 \%)$ & $389(27.2 \%)$ & $162(35.2 \%)$ & $188(8.1 \%)$ & \\
\hline High & $202(15.5 \%)$ & 705 (49.2\%) & $161(35.0 \%)$ & $21(0.9 \%)$ & \\
\hline
\end{tabular}

*chi square test and ANOVA test. N: number, SD: standard deviation

\section{DISCUSSION}

This study revealed two important associations between mental disorders and spirituality. We confirmed that attaching high importance to spiritual values was associated with a higher prevalence of current depression, irrespective of causality. In contrast, a higher importance placed on spiritual values was also associated with less current alcohol use disorder. These results are similar to those of a previous Canadian study that analyzed mental disorder prevalence data using the CIDI. ${ }^{11}$ However, our study did not confirm any associations between spirituality/religion and past mental disorders or indicate any significant relationship between anxiety disorder and spiritual values.
Positive associations between mental disorders and spiritual values have been interpreted in two ways. ${ }^{12}$ The first perspective is that strong spiritual values are often associated with and may lead to a high prevalence of mental disorders. The other assumption is that mental illness leads individuals to seek spirituality and religion to help manage their psychological issues. To elucidate the causal relationship between mental disorders and religion/spirituality, we referred to individuals who had experienced one or more mental disorder episodes within the 12 months prior to the study but who did not meet the diagnostic criteria for a current psychiatric disorder as having a past disorder. ${ }^{11}$ Our findings that spirituality is associated with current depression, but not with past depression suggest that individuals with currently high 
levels of depression have a stronger tendency to place more importance on spiritual values, but the individuals who had overcome past depression does not. In other words, a depressive episode motivates patients to seek out God and religion as a way of coping with their illness. Several studies have suggested that religious activities, such as worship attendance, may play a role in combating depression. ${ }^{11,13}$

Because we did not include worship frequency, which is

Table 2. The prevalence of mental disorder according to the type of religion

\begin{tabular}{lcccc}
\hline Prevalence $(95 \%$ CI $)$ & Buddhists & Protestants & Catholics & Atheists \\
\hline Lifetime & & & & \\
MDD & $4.4(3.30-5.52)$ & $5.6(4.43-6.79)$ & $6.8(4.51-9.05)$ & $4.2(3.43-4.88)$ \\
$\quad$ Single & $3.5(2.51-4.49)$ & $4.2(3.21-5.27)$ & $6.4(4.15-8.56)$ & $3.1(2.46-3.72)$ \\
$\quad$ Recurrent & $0.9(0.40-1.43)$ & $1.4(0.77-1.96)$ & $0.4(0-1.01)$ & $1.1(0.69-1.44)$ \\
Anxiety disorder & $10.6(8.97-12.29)$ & $12.0(10.31-13.63)$ & $12.3(9.33-15.25)$ & $8.1(7.08-9.06)$ \\
Alcohol use disorder & $12.8(10.96-14.57)$ & $10.8(9.21-12.39)$ & $13.3(10.28-16.42)$ & $17.2(15.87-18.61)$ \\
Any mental disorder & $30.1(27.65-32.64)$ & $28.9(26.58-31.25)$ & $31.4(27.18-35.62)$ & $32.0(30.32-33.73)$ \\
One-year & & & & \\
MDD & $2.0(1.22-2.73)$ & $2.7(1.84-3.49)$ & $3.2(1.60-4.76)$ & $1.8(1.33-2.31)$ \\
$\quad$ Single & $1.5(0.87-2.20)$ & $1.9(1.17-2.57)$ & $2.8(1.28-4.25)$ & $1.4(0.96-1.82)$ \\
$\quad$ Recurrent & $0.5(0.10-0.85)$ & $0.9(0.37-1.34)$ & $0.5(0-1.08)$ & $0.5(0.21-0.71)$ \\
Anxiety disorder & $8.3(6.80-9.78)$ & $8.1(6.69-9.49)$ & $8.7(6.15-11.23)$ & $5.6(4.77-6.45)$ \\
Alcohol use disorder & $5.1(3.92-6.31)$ & $4.5(3.40-5.51)$ & $7.1(4.73-9.37)$ & $7.2(6.25-8.14)$ \\
Any mental disorder & $20.0(17.80-22.20)$ & $18.1(16.13-20.15)$ & $21.5(17.72-25.3)$ & $20.0(18.56-21.51)$ \\
\hline
\end{tabular}

MDD: major depressive disorder, CI: confidence interval

Table 3. Multiple logistic regression for relation between the type of religion and prevalence of mental disorders (with adjusted sex and age)

\begin{tabular}{|c|c|c|c|c|}
\hline Prevalence (95\% CI) & Buddhists & Protestants & Catholics & Atheists*** \\
\hline \multicolumn{5}{|l|}{ Lifetime } \\
\hline MDD & $0.839(0.603-1.167)$ & $1.150(0.858-1.542)$ & $1.348(0.896-2.029)$ & \\
\hline Single & $0.913(0.630-1.324)$ & $1.153(0.825-1.612)$ & $1.719(1.117-2.645)^{* *}$ & \\
\hline Recurrent & $0.645(0.324-1.285)$ & $1.128(0.634-2.004)$ & $0.317(0.075-1.335)$ & \\
\hline Anxiety disorder & $1.115(0.887-1.401)$ & $1.306(1.057-1.613)^{*}$ & $1.309(0.959-1.787)$ & \\
\hline Alcohol use disorder & $0.961(0.786-1.175)$ & $0.750(0.614-0.917)^{* *}$ & $1.078(0.800-1.454)$ & \\
\hline Any Mental Disorder & $1.038(0.894-1.204)$ & $0.983(0.853-1.133)$ & $1.156(0.931-1.436)$ & \\
\hline \multicolumn{5}{|l|}{1 year (current) } \\
\hline MDD & $0.824(0.506-1.343)$ & $1.230(0.805-1.881)$ & $1.374(0.762-2.477)$ & \\
\hline Single & $0.831(0.477-1.448)$ & $1.100(0.670-1.808)$ & $1.535(0.809-2.912)$ & \\
\hline Recurrent & $0.796(0.291-2.174)$ & $1.692(0.753-3.802)$ & $0.814(0.180-3.676)$ & \\
\hline Anxiety disorder & $1.275(0.982-1.655)$ & $1.238(0.964-1.590)$ & $1.306(0.908-1.877)$ & \\
\hline Alcohol use disorder & $0.953(0.711-1.277)$ & $0.758(0.565-1.017)$ & $1.402(0.946-2.079)$ & \\
\hline Any Mental Disorder & $1.080(0.910-1.280)$ & $0.956(0.809-1.129)$ & $1.217(0.951-1.557)$ & \\
\hline \multicolumn{5}{|l|}{ Past } \\
\hline MDD & $0.861(0.556-1.332)$ & $1.077(0.726-1.597)$ & $1.301(0.754-2.247)$ & \\
\hline Single & $0.994(0.607-1.626)$ & $1.223(0.783-1.910)$ & $1.830(1.038-3.226)^{*}$ & \\
\hline Recurrent & $0.540(0.209-1.397)$ & $0.767(0.330-1.781)$ & $0.000(0.000-)$. & \\
\hline Anxiety disorder & $0.746(0.477-1.167)$ & $1.423(0.993-2.039)$ & $1.268(0.736-2.184)$ & \\
\hline Alcohol use disorder & $0.959(0.747-1.231)$ & $0.779(0.606-1.000)$ & $0.826(0.550-1.239)$ & \\
\hline Any Mental Disorder & $0.936(0.737-1.188)$ & $0.977(0.781-1.224)$ & $0.894(0.616-1.298)$ & \\
\hline
\end{tabular}

${ }^{*} \mathrm{p}<0.05,{ }^{* *} \mathrm{p}<0.01,{ }^{* * *}$ reference axis. MDD: major depressive disorder, CI: confidence interval 
associated with different types of belief in God across religions, our study provides no information on how religious activity is related to depression. However, we can posit that current depression can result in people placing a high importance on spiritual values regardless of the frequency of their attendance at religious services. It is natural that a serious illness could cause an individual to seek spiritual support. ${ }^{11}$

Strong spirituality was associated with a significantly lower odds ratio of current alcohol use disorder. This pattern differs from those observed for current major mental disorders. These results are in accordance with prior studies indicating that a high level of religious involvement predicts a reduced risk for alcohol misuse. ${ }^{14,15}$ It is not difficult to understand

Table 4. Multiple logistic regression for relation between spirituality and past and current mental disorders (with adjusted sex, age and type of religion)

\begin{tabular}{ll}
\hline & Spirituality \\
\hline Prevalence (95\% CI) & \\
Current & $1.266(1.040-1.468)^{*}$ \\
MDD & $1.122(0.923-1.364)$ \\
$\quad$ Single & $1.775(1.214-2.597)^{* *}$ \\
$\quad$ Recurrent & $1.043(0.945-1.151)$ \\
Anxiety disorder & $0.875(0.779-0.982)^{*}$ \\
Alcohol use disorder & $0.955(0.894-1.020)$ \\
Any Mental Disorder & \\
Past & $1.081(0.925-1.264)$ \\
MDD & $1.026(0.862-1.221)$ \\
$\quad$ Single & $1.322(0.925-1.889)$ \\
$\quad$ Recurrent & $0.950(0.815-1.106)$ \\
Anxiety disorder & $0.912(0.827-1.006)$ \\
Alcohol use disorder & $0.985(0.900-1.078)$ \\
Any Mental Disorder &
\end{tabular}

${ }^{*} \mathrm{p}<0.05,{ }^{* *} \mathrm{p}<0.01$. MDD: major depressive disorder, CI: confidence interval that when individuals are currently under the influence of alcohol, it is unlikely that they are able to reframe what is happening to them in terms of spiritual values. ${ }^{11}$ Negative relationship between alcohol misuse and spiritual values is also supported by our finding that the highest levels of alcohol use disorder were in atheists.

The associations between religion/spirituality and anxiety disorders were insignificant and similar to those of prior studies. ${ }^{11,15,16}$ Though we did not analyze the data by dividing anxiety disorders into panic disorders, social phobias and similar categories as prior studies have, we found no significant association between spiritual values and anxiety disorder, both current and past. We do not know whether anxiety is unassociated with spirituality, but anxiety disorder might be regarded as less severe than depression in terms of prompting a search for meaning or an understanding of hardships through spiritual values. ${ }^{16}$ However, this interpretation should be approached with caution because of the overlap between depressive and anxiety symptoms.

There have been epidemiological observations that members of some religious groups appear to be at elevated risk for certain mental disorders. ${ }^{17}$ However, because almost all of these studies used a Christian population as their baseline, we cannot apply their conclusions to other countries that have different religious compositions. By using atheists as a reference point, our study revealed that religious affiliation is associated with the prevalence of mental disorders in several ways. The meaningful results are as follows: First, there were no significant differences in the rates of current mental disorders of religious affiliation group regardless of type of religion compared with the no affiliation group. Second, a past history of a single episode of depression was statistically meaningful only in Catholics. Third, Protestants presented a higher lifetime prevalence odds ratio for anxiety disorder and a lower odds ratio for alcohol use disorder compared with

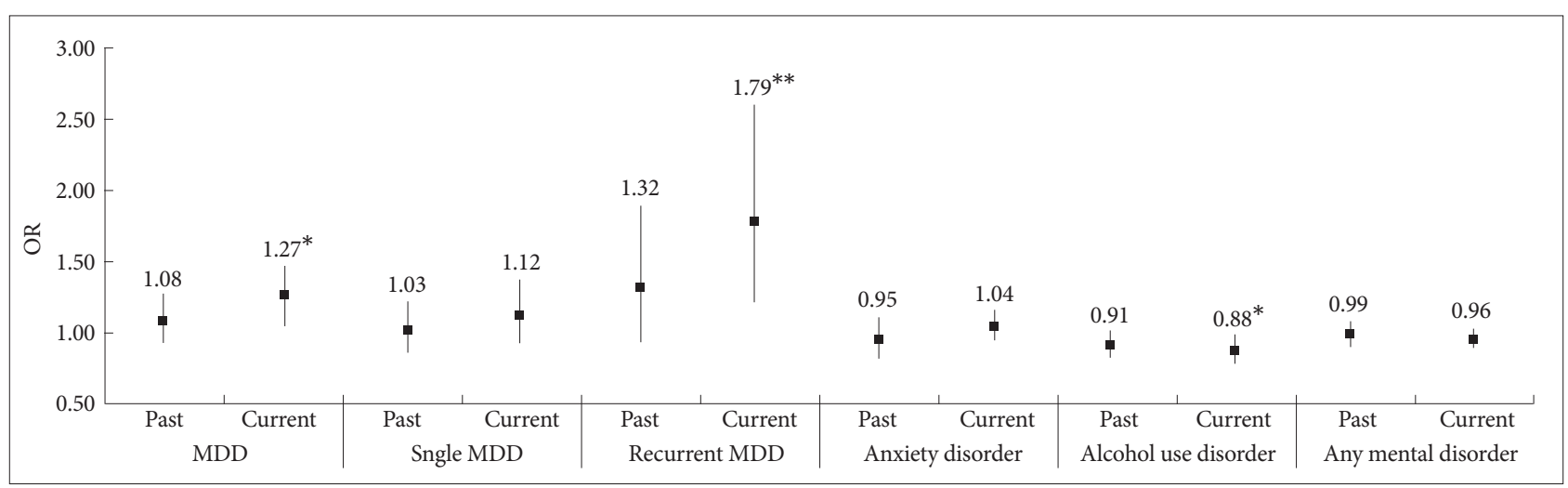

Figure 1. The relation between spirituality and past and current mental disorders (with adjusted sex, age, type of religion). ${ }^{*} p<0.05$, $* * p<0.01$. MDD: major depressive disorder. 
atheists.

The unadjusted prevalence data indicate that the highest lifetime prevalence for a single episode of depression was associated with Catholic religious affiliation. In contrast, the same group had the lowest lifetime prevalence of recurrent depression, though the difference was not significant in the logistic regression analysis. Because we have no information regarding the timing of the onset of depression and the entry into religious life, it is not clear whether depressed persons are eager to become Catholics. However, the significant association of Catholicism with past depression leads us to a particular interpretation. Catholic beliefs, for example, may have a healing effect on depression or may prevent a relapse. This hypothesis is supported by the absence of a significant current ethnic religion affiliation among Koreans, who are allowed to freely select their own religious beliefs. In other words, their religion might not be determined by their parents but rather by the individuals themselves; therefore, there is a tendency to become involved with religion with increasing age.

The lower odds ratio of lifetime alcohol use disorder in Protestants is relatively easy to explain ${ }^{18}$ in terms of the tenets of many Protestant religious beliefs that aim to restrain adherents from drinking alcohol, though the observance of this restriction may vary between individuals. This hypothesis is supported by a comparison with Catholics, who are relatively lenient toward drinking according to our results. Though the odds ratio for current alcohol use disorder in Catholics compared with atheists was not significant, the upper limit of the $95 \%$ confidence interval was 1.000 . Studies that have defined "religious" as adherence to Christian tenets have unanimously found that religious individuals are less likely to abuse alcohol. ${ }^{4}$

The lifetime prevalence of anxiety disorder was higher among this survey's Protestant respondents compared with the atheists. People with anxiety disorder may attend church to relieve anxiety. In contrast, some Christian doctrines, such as the belief that people are born with original sin, may evoke anxiety among believers. Inconsistent with our results, a previous study has reported a high rate of anxiety disorder among young adults with no religious affiliation. ${ }^{16}$

Our study has several limitations. First, although we examined a large, nationally representative population using the K-CIDI 2.1, this was essentially a cross-sectional study. Therefore, our choice to divide lifetime prevalence into current and past prevalence was based on incomplete evidence used to infer temporal associations between mental health and religious beliefs/spirituality. More valid and rational explanations concerning directionality need to be explored in prospective studies of large, general populations. Second, we only evaluated spirituality in one survey question. Because of the different cultures and rituals across religions, we predicted that this method would provide a more tailored approach to elucidating the association between religion and mental health. Nonetheless, we question whether our study evaluated the correct "spirituality" because measures of spiritual values are not well established. ${ }^{19}$ Third, although we controlled for sex and age, many confounding variables were not explored, such as cultural factors, family experiences, and environmental factors.

The results of our study may reflect the possibility that a depressive episode motivates people to search for spiritual meaning or the power of God. Spirituality might not have been as highly regarded when the individual first became depressed, but over time, spiritual values may help an individual overcome depression or become less vulnerable to relapse. However, this interpretation fails to provide firm evidence for why a longing for God appeared to occur only among the surveyed Catholics. Thus, further research is required.

\section{Acknowledgments}

This work was funded by the Korean Ministry of Health and Welfare in 2001. Technical support was provided by Dr. Harry Minas, Associate Professor, Center for International Mental Health, School of Population Health, the University of Melbourne, Victoria, Australia.

\section{REFERENCES}

1. Bergin AE. Religiosity and mental health: a critical reevaluation and meta-analysis. Prof Psychol Res Pract 1983;14:170-184.

2. Witter RA, Stock WA, Okun MA, Haring MJ. Religion and subjective well-being in adulthood: a quantitative synthesis. Rev Relig Res 1985; 26:332-342.

3. Spika B, Hood RW Jr, Gorsuch RL. The Psychology of Religion: An Empirical Approach. Englewood Cliffs, NJ: Prentice Hall; 1985.

4. Koenig HG, Larson DB. Religion and mental health: evidence for an association. Int Rev Psychiatry 2001;13:67-78.

5. Yinger JM. Pluralism, religion and secularism. J Sci Study Relig 1967; 6:17-28.

6. Korean National Statistical Office. The Report of Population and Housing Census 2000. Seoul: Korean National Statistical Office; 2000.

7. Koenig HG, McCullough M, Larson DB. Handbook of Religion and Health: A Century of Research Reviewed. New York: Oxford University Press; 2001.

8. American Psychiatric Association. Diagnostic and Statistical Manual of Mental Disorders, 4th Edtion. Washington DC: American Psychiatric Press, 1994, p.273-290.

9. Cho MJ, Hahm BJ, Suh DW, Hong JP, Bae JN, Kim JK, et al. Development of a Korean version of Composite International Diagnostic Interview (K-CIDI). J Korean Neuropsychiatr Assoc 2002;41:123-137.

10. Cho MJ, Kim JK, Jeon HJ, Suh T, Chung IW, Hong JP, et al. Lifetime and 12-month prevalence of DSM-IV psychiatric disorders among Korean adults. J Nerv Ment Dis 2007;195:203-210.

11. Baetz M, Bowen R, Jones G, Koru-Sengul T. How spiritual values and worship attendance relate to psychiatric disorders in the Canadian population. Can J Psychiatry 2006;51:654-661.

12. Baetz M, Griffin R, Bowen R, Koenig HG, Marcoux E. The association between spiritual and religious involvement and depressive symptoms in a Canadian population. J Nerv Ment Dis 2004;192:818-822. 
13. Kendler KS, Gardner CO, Prescott CA. Clarifying the relationship between religiosity and psychiatric illness: the impact of covariates and the specificity of buffering effects. Twin Res 1999;2:137-144.

14. Koenig HG, George LK, Meador KG, Blazer DG, Ford SM. Religious practices and alcoholism in a southern adult population. Hosp Community Psychiatry 1994;45:225-231.

15. Kendler KS, Liu XQ, Gardner CO, McCullough ME, Larson D, Prescott CA. Dimensions of religiosity and their relationship to lifetime psychiatric and substance use disorders. Am J Psychiatry 2003;160:496503.

16. Koenig HG, Ford SM, George LK, Blazer DG, Meador KG. Religion and anxiety disorder: an examination and comparison of associations in young, middleaged, and elderly adults. J Anxiety Disord 1993;7:321342.

17. McCullough ME, Larson DB. Religion and depression: a review of the literature. Twin Res 1999;2:126-136.

18. Edlund MJ, Harris KM, Koenig HG, Han X, Sullivan G, Mattox R, et al. Religiosity and decreased risk of substance use disorders: is the effect mediated by social support or mental health status? Soc Psychiatry Psychiatr Epidemiol 2010;45:827-836.

19. Moreira-Almeida A, Neto FL, Koenig HG. Religiousness and mental health: a review. Rev Bras Psiquiatr 2006;28:242-250. 